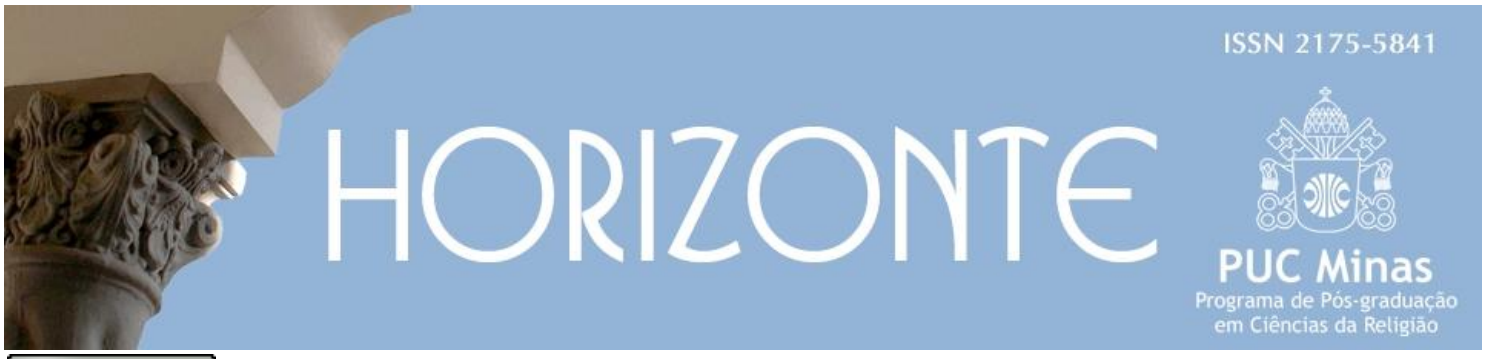

\title{
Pentecostalismos, racismo e Direitos Humanos
}

\author{
Pentecostalisms, racism, and Human Rights
}

David Mesquiati de Oliveira*

Kenner Roger Cazotto Terra**

\begin{abstract}
Resumo
Os pentecostalismos significaram a ruptura com a antropologia protestante refém da epistemologia da Modernidade. Como explica Harvey Cox, esses movimentos americanos dos primeiros anos do século XX preencheram o déficit extático deixado pelos evangélicos, apontando em direção do sistema afetivo de conhecimento da realidade, uma epistemologia afetiva. Se por um lado a experiência pentecostal animou o deslocamento da margem para o centro da corporeidade, por outro, os corpos violentados e subjugados tornaram-se visíveis e empoderados, porque grupos marginalizados, excluídos pelo establishment protestante americano e brasileiro, foram e são protagonistas. Apresenta-se os movimentos pentecostais como presença no mundo e prática religiosa reveladora da defesa de direitos fundamentais, especialmente na militância da justiça racial, o que não significa uma defesa teórica, mas vivências comunitárias de corpos excluídos que ganham status pneumáticos. O ensaio discute a relação entre religião, Direitos Humanos e as questões raciais, apontando como os pentecostalismos representam intuições para uma sociedade mais fraterna e igualitária.
\end{abstract}

Palavras-chave: Pentecostalismo. Racismo. Direitos Humanos.

\begin{abstract}
Pentecostalism meant a break with Protestant anthropology hostage to the epistemology of Modernity. As Havey Cox explains, these American movements in the early years of the 2oth century filled the ecstatic deficit left by evangelicals, pointing towards the affective system of knowledge of reality, an affective epistemology. If, on the one hand, the Pentecostal experience encouraged the shift from the margin to the center of corporeality, on the other, the violated and subjugated bodies became visible and empowered, because marginalized groups, excluded by the American and Brazilian Protestant establishment, were and are protagonists. Pentecostal movements are presented as a presence in the world and religious practice that reveals the defense of fundamental rights, especially in the militancy experience of racial justice, which does not mean a theoretical defense, but community experiences of excluded bodies that gain pneumatic status. The essay discusses the relationship between religion, human rights and racial issues, pointing out how Pentecostalism represents intuitions for a more fraternal and egalitarian society.
\end{abstract}

Keywords: Pentecostalism. Racism. Human Rights.

Artigo submetido em 30 de novembro de 2020 e aprovado em 17 de maio de 2021.

* Doutor em Teologia pela PUC-Rio. Professor da Faculdade Unida de Vitória. País de origem: Brasil. E-mail: david@faculdadeunida.com.br

** Doutor em Ciências da Religião pela UMESP. Professor da Faculdade Unida de Vitória. País de origem: Brasil. E-mail: kenner@faculdadeunida.com.br 


\section{Introdução}

O movimento pentecostal representa uma significativa parcela dos cristãos evangélicos no Brasil. O Censo Demográfico de 2010 revelou a mudança do quadro religioso brasileiro (PALHARES, 2019, p. 20), no qual, embora majoritário, o catolicismo apresenta contínua diminuição de adeptos, ao mesmo tempo, em que os evangélicos avançam desde o ano 2000 em franco alargamento numérico. Se em 1991 os evangélicos representavam 9,0\% da população, em 2000 já eram 15,4\% e em 2010 chegaram à marca de 22\%, dos quais 60\% se declararam de origem pentecostal, superando os 18,5\% dos evangélicos de missão (INSTITUTO BRASILEIRO DE GEOGRAFIA E ESTATÍSTICA, 2012). Os números mostram a dinâmica e potência expansionista dos movimentos cristãos extáticos (OLIVEIRA; TERRA, 2018), cujo discurso é perpassado pela performatização da fé, valorização da experiência e vivência coletiva.

Estabelecidos na fronteira entre os racionalismos cessacionista e liberal (YONG, 2005), os pentecostalismos significaram a ruptura com a antropologia protestante refém da epistemologia da Modernidade. Como explica Havey Cox (1995), esses movimentos americanos dos primeiros anos do século XX preencheram o déficit extático deixado pelos evangélicos, apontando em direção do sistema afetivo de conhecimento da realidade, que no dizer de Smith (2003) seria a epistemologia afetiva. Se por um lado a experiência pentecostal animou o deslocamento da margem para o centro da corporeidade, por outro, os corpos violentados e subjugados tornaram-se vivíveis e empoderados, porque grupos marginalizados, excluídos pelo establishment protestante americano e brasileiro, foram e são protagonistas.

A partir dessas questões históricas e epistemológicas, este ensaio apresenta os movimentos pentecostais como presença no mundo e prática religiosa reveladora da defesa de direitos fundamentais, especialmente na militância da justiça racial, o que não significa uma defesa teórica, mas vivência comunitária de corpos excluídos que ganham status pneumáticos. Inicialmente, será discutida a relação entre religião e direitos humanos, avançando para as reflexões a respeito dos direitos fundamentais e as questões raciais e, por fim, 
destacar como os pentecostalismos têm potencial de representar intuições para uma sociedade mais fraterna e igualitária.

\title{
1 Direitos Humanos e religião
}

Boaventura de Sousa Santos (2014, p. 15), em uma contundente crítica, começa seu argumento explicando serem os Direitos Humanos a linguagem da dignidade humana. O autor português problematiza o caráter hegemônico da construção desse conceito, porque é parte da mesma hegemonia que consolida e legitima formas múltiplas de opressão. Sua resposta a esse problema é autoexplicativa:

\begin{abstract}
A busca de uma concepção contra-hegemônica dos direitos humanos deve começar por uma hermenêutica de suspeita em relação aos direitos humanos tal como são convencionalmente entendidos e defendidos, isto é, em relação às concepções dos direitos humanos mais diretamente vinculadas à matriz liberal e ocidental. (SANTOS, 2014, p. 16).
\end{abstract}

Criticando o teor universalista e, consequentemente, colonialista da genealogia dos Direitos Humanos, Boaventura expõe a contradição da abissal divisão entre as sociedades metropolitanas e coloniais, pois, "enquanto discurso de emancipação, os direitos humanos foram historicamente concebidos para vigorar apenas do lado de cá da linha abissal, nas sociedades metropolitanas." (SANTOS, 2014, p. 17). Aprofundando a discussão, o autor ainda aponta as quatro bases ilusórias que fortalecem o consenso de serem os Direitos Humanos os princípios reguladores na concepção de uma sociedade justa: a teleológica, o triunfalismo, a descontextualização e o monolitismo (SANTOS, 2014, p. 18). É a partir dessas provocações que Boaventura indicará o lugar da religião na construção contra hegemônica dos Direitos Humanos.

À luz das intuições do autor de Se Deus fosse um ativista dos direitos humanos (2014), as teologias políticas pluralistas, a despeito das fundamentalistas negaram-lhe valor, seriam uma grande contribuição para a linguagem dos direitos fundamentais, e os movimentos pentecostais poderiam ser incluídos nessas fileiras. Além do que, desenvolvendo a genealogia da moderna discussão dos Direitos Humanos, cujas bases se estabelecem no 
conceito da "dignidade humana", chega-se às tradições judaicas e gregas (COMPARATO, 1997). O jurista Konder Comparato afirma:

A respeito da dignidade humana, o pensamento ocidental é herdeiro de duas tradições parcialmente antagônicas: a judaica e a grega. A grande (e única) invenção do povo da Bíblia, uma das maiores, aliás, de toda a história humana, foi a idéia [sic] da criação do mundo por um Deus único e transcendente. Os deuses antigos, de certa forma, faziam parte do mundo, como super-homens. Iahweh, muito ao contrário, como criador de tudo o que existe, é anterior e superior ao mundo [...]. (COMPARATO, 1997, p. 12).

O jurista e historiador do direito avança e confessa que a teologia da criação, por tratar a humanidade como imagem da divindade, instalou-se na cultura ocidental tornando a sacralidade da vida parte constituinte dos principais movimentos humanistas (COMPARATO, 1997, p. 13). Conseguintemente, a recepção da tradição judaico-cristã esteve na formatação da afirmação teológico-filosófica do humano como sujeito de direitos - contudo, para Boaventura, mesmo servindo como fonte de dignidade humana, foi exatamente essa tradição que significou a hegemonia e universalismo dos Direitos Humanos. Acrescentando, Jean Rivero e Hugues Moutouh (2006) afirmam a íntima relação dos Direitos Humanos e a tradição judaico-cristã:

[...] a própria noção de direitos do homem supõe uma civilização em que a dignidade da pessoa humana se mostra em evidência[...] o cristianismo, nesse ponto herdeiro da tradição judaica enriquecida e renovada, deu-lhe os fundamentos que progressivamente a impuseram. (RIVERO; MOUTOUH, 2006, p. 37).

Por outro lado, pensando o lugar dos protestantismos e da Reforma, especialistas em termos jurídicos apontam a leitura desses movimentos de interpretação da Bíblia como grande responsável, tanto para o desenvolvimento da Modernidade como das discussões entranhadas do germe do que seria o "jusnaturalismo":

Ainda que, de um lado, inúmeros teóricos admitam uma certa dificuldade em assinalar pontos de interação entre a Reforma e o Humanismo Renascentista, por outro, não se pode deixar de reconhecer a influência do protestantismo na gênese do Capitalismo moderno, na formulação da mentalidade livre individualista, na valoração da consciência moral, na contribuição da filosofia dos direitos humanos e, fundamentalmente, no impulso para a moderna concepção de jusnaturalismo. (WOLKMER, 2005, p. 21). 
Se por um lado esses autores indicam o lugar da religião em geral e do Protestantismo, em particular, no germe da linguagem dos direitos universais, Boaventura mostra que as teologias pluralistas seriam, no que lhe concerne, o lugar de maior aproximação do que chamaria de Direitos Humanos com rosto contra-hegemônico. Sobre a presença no espaço público, destaca dois polos, sendo um, a partir da teologia pluralista, e o outro, da teologia fundamentalista. Quanto ao critério de intervenção religiosa, haveria as teologias tradicionalistas e as progressistas. Enquanto as tradicionalistas têm suas raízes no passado, e através do qual pensam sua intervenção, o que significa preservar as estruturas como estão, as progressistas possuem traços subversivos e de rompimento (SANTOS, 2014, p. 47). Boaventura não trata somente do cristianismo, mas quando didaticamente apresenta as diferenças e tensões dessas perspectivas teológicas, ele afirma:

No Cristianismo, uma teologia tradicional significa, por exemplo, que a distinção entre religião dos oprimidos e a religião dos opressores, não possa ser aceita. $\mathrm{O}$ que deu outra perspectiva é visto como a religião do opressor - uma religião espiritualista, burguesa, sem posição crítica em face das injustiças estruturais - é considerado o padrão de experiência religiosa legítima, ao mesmo tempo que a religião dos oprimidos é estigmatizada e ignorada. (SANTOS, 2014, p. 48).

Os movimentos pentecostais e carismáticos representam exatamente a diluição dessa superficial leitura tradicional, porque mostram historicamente a presença desse cristianismo oprimido, de classes excluídas e relativiza as divisões raciais. As comunidades pentecostais mostravam na prática como esse abismo injusto sempre foi notável, e a hostilidade pela qual passavam tinha exatamente fonte nesse olhar preconceituoso e indiferente, ao mesmo tempo, em que resistiam, sob a orientação de uma pneumatologia do amor, à violação dos direitos humanos. Gedeon Alencar e Maxwell Fajardo (2016) conseguem descrever muito bem essas relações, violências discursivas e impacto dos pentecostalismos:

O movimento da Azusa Street foi descrito pelos jornais da época como "orgia". Mesmo sem nenhuma conotação sexual, o movimento teve esse estigma porque reunia negros e brancos. Para a infame sociedade segregacionista norte-americana da época, uma reunião como essa somente podia ser chamada assim. Internamente, o movimento se via como ação do Espírito em que todas e todos podiam ter acesso. Absolutamente qualquer pessoa independentemente de gênero, classe ou raça. Na época, nos EUA, negros e mulheres não votavam, não 
tinham acesso à educação, não podiam andar nas mesmas calçadas, compartilhar os mesmos recintos públicos ou usar os mesmos bebedouros dos brancos, além do que lhes eram negados os mais elementares direitos civis - porém agora podiam, ombro a ombro com os brancos, receber o Espírito, cantar, orar e pregar juntos. (ALENCAR; FARJADO, 2016, p. 102).

Alvos das teologias tradicionalistas, esses movimentos eram tratados com desconfiança. A identificação "orgiástica”, nada mais era do que estratégia retórica de desqualificação, por estarem rompendo as estruturas racistas americanas. Por essa razão, na prática, os pentecostais devem ser enfileirados nos grupos progressistas, mesmo que não se identifiquem exatamente assim, especialmente no contexto das questões raciais e econômicas, pois na força do Espírito romperam com divisões estabelecidas socialmente e legitimadas pelas comunidades cristãs tradicionais, ao menos em sua fase inicial e ainda vigente em setores das margens (OLIVEIRA; ROCHA, 2018).

\section{Direitos Humanos e questão racial}

O preâmbulo da Declaração Universal dos Direitos Humanos (DUDH) (ORGANIZAÇÃO DAS NAÇÕES UNIDAS, 1948), documento histórico e essencial para as nações estabelecerem os parâmetros dos direitos fundamentais, afirma antes de qualquer coisa a inviolável dignidade de toda pessoa humana como resposta às históricas monstruosidades testemunhadas no mundo. Com proposições retórico-argumentativas, o documento afirma nas primeiras linhas:

\footnotetext{
Considerando que o reconhecimento da dignidade inerente a todos os membros da família humana e de seus direitos iguais e inalienáveis é o fundamento da liberdade, da justiça e da paz no mundo, Considerando que o desprezo e o desrespeito pelos direitos humanos resultaram em atos bárbaros que ultrajaram a consciência da Humanidade e que o advento de um mundo em que os todos gozem de liberdade de palavra, de crença e da liberdade de viverem a salvo do temor e da necessidade foi proclamado como a mais alta aspiração do ser humano comum (ONU, 1948, [n.p.]).
}

Essas afirmações, nas quais a existência humana e seus direitos são tratados com força de ordenação jurídica, e cabe aos Estados Democráticos preservá-los, apresenta a inalienável dignidade humana. No que lhe concerne, seguindo o espírito da universalização do direito à vida, no Artigo II, inciso 1, encontramos o alcance dessa Declaração: 
Todo ser humano tem capacidade para gozar os direitos e as liberdades estabelecidos nesta Declaração, sem distinção de qualquer espécie, seja de raça, cor, sexo, idioma, religião, opinião política ou de outra natureza, origem nacional ou social, riqueza, nascimento, ou qualquer outra condição (ONU, 1948).

A universalização das proposições da Declaração transborda às fronteiras, entre outras coisas, de raça e cor, o que possibilita enfrentar as estruturas racistas e escravocratas, como expressa o Artigo IV (ONU, 1948). Na esteira do desenvolvimento dos direitos fundamentais, há o Estatuto da Igualdade Racial (BRASIL, [2010]), publicado em 20 de julho de 2010. Esse é um bom exemplo da aplicação legal dos direitos e enfrentamentos às formas de injustiça racial:

Parágrafo único. Para efeito deste Estatuto, considera-se: I discriminação racial ou étnico-racial: toda distinção, exclusão, restrição ou preferência baseada em raça, cor, descendência ou origem nacional ou étnica que tenha por objeto anular ou restringir o reconhecimento, gozo ou exercício, em igualdade de condições, de direitos humanos e liberdades fundamentais nos campos político, econômico, social, cultural ou em qualquer outro campo da vida pública ou privada; II - desigualdade racial: toda situação injustificada de diferenciação de acesso e fruição de bens, serviços e oportunidades, nas esferas pública e privada, em virtude de raça, cor, descendência ou origem nacional ou étnica; III - desigualdade de gênero e raça: assimetria existente no âmbito da sociedade que acentua a distância social entre mulheres negras e os demais segmentos sociais; IV população negra: o conjunto de pessoas que se autodeclaram pretas e pardas, conforme o quesito cor ou raça usado pela Fundação Instituto Brasileiro de Geografia e Estatística (IBGE), ou que adotam autodefinição análoga; V - políticas públicas: as ações, iniciativas e programas adotados pelo Estado no cumprimento de suas atribuições institucionais; VI - ações afirmativas: os programas e medidas especiais adotados pelo Estado e pela iniciativa privada para a correção das desigualdades raciais e para a promoção da igualdade de oportunidades (BRASIL, [2010]).

A dignidade humana como valor inquestionável se desdobra em discussões necessariamente raciais e cada Estado desenvolve sua política de aplicação e enfrentamento das expressões de violência que neguem os direitos a todos e todas. Quando se observa os movimentos pentecostais e carismáticos, essa sensibilidade parece se estabelecer exatamente na prática eclesial e historicamente se desenvolveu nas comunidades espalhadas por várias regiões, por vezes, nas periferias das grandes cidades. Todavia, a origem dos pentecostais e seu ethos apontam para a antecipação de diversas cláusulas desses documentos tão importantes. Por isso, pensar a origem do pentecostalismo e seus traços fundamentais pode ajudar na percepção do lugar 
que tiveram as práticas integradoras que questionaram o status quo e reivindicaram justiça racial.

\section{Origem e ethos pentecostal}

O pentecostalismo moderno, movimento plural e global, tem suas raízes em diversas experiências históricas. Alguns autores localizam a origem do movimento no Bethel Bible College, em Topeka, Kansas, liderado pelo pregador de origem holiness Charles Fox Parham (1873-1929). Cronologicamente, seu início se deu em janeiro de 1901 na experiência de Agnes Ozman e outros estudantes que, após algumas reuniões no instituto bíblico, falaram em outras línguas. Na ocasião, acreditaram, entre eles o próprio Parham, ser xenolalia, porque a primeira pentecostal teria falado em chinês. A partir daí, o pregador Parham começou a ensinar esse fenômeno como evidência inicial do batismo no Espírito Santo e a marca de que a volta de Cristo estava próxima, impulsionando grande movimento missionário, cujo objetivo seria expandir essa doutrina e a conversão final, a última colheita (PARHAM, 2020). No entanto, antes dele, glossolalia, curas e a doutrina do "batismo no fogo" já eram comuns.

Muitos autores tratam o avivamento da Rua Azusa, em Los Angeles, Califórnia (1906-1909), liderado pelo afro-americano William J. Seymour, como início do movimento pentecostal moderno. Cinco anos depois da experiência da Bethel Bible College, em um antigo prédio em que aconteciam reuniões lideradas pelo pastor Seymour, negros e brancos, homens e mulheres, viveram as mesmas experiências de Topeka. Depois disso, aquele espaço ficou aberto a todos que desejassem ser cheios do poder do Espírito Santo, designação característica do movimento pentecostal para descrever sua vivência. Milhares de cristãos de várias igrejas visitaram as reuniões da congregação muitas vezes por semana. A Rua Azusa tornou-se uma espécie de “Jerusalém americana” para os pentecostais de todo o mundo (BARTOȘ, 2015, p. 25). Nos primeiros anos, Seymour estava comprometido com a afirmação da glossolalia como evidência inicial do batismo com o Espírito Santo. Depois de algumas querelas com seu antigo professor Parham, o líder negro pentecostal começou a afirmar em escritos que as línguas eram uma das evidências, mas a evidência estaria na vida cotidiana (McGEE, 2017). Mesmo sem negar as línguas como genuína 
experiência do batismo do Espírito Santo, Seymour começou a identificar o divino amor por todos como a grande marca da presença do Espírito (OLIVERIO, 2012, p. 10). Segundo explica o teólogo pentecostal Cecil M. Robeck Jr., o movimento liderado por Seymour tornou-se um exemplo profético de promoção e serviço aos marginalizados em um tempo de fortes tensões raciais e socioeconômicas, além de promover o papel da igualdade da liderança masculina e feminina. Esse movimento empoderou pobres, minorias étnicas e mulheres. O avivamento da Rua Azusa implantou o igualitarismo como modelo para o pentecostalismo (ROBECK JR., 2006, p. 4).

Enquanto as outras expressões protestantes se acomodaram ao mundo Moderno e acolhiam com mais perspicácia a classe média vitoriana, o Pentecostalismo, negando assimilação social (negação de mundo), constituía-se uma proposta crítica à sociedade moderna urbana-industrial capitalista. Nas origens, os pentecostais atraíram o povo das margens em regiões menos afetadas pela modernização, e se espalharam entre os grupos das classes empobrecidas (ARCHER, 2009, p.22-230). Ao descrever as origens do pentecostalismo, Kenneth Archer afirma ser um movimento formado pelos excluídos do mainstream social com nascedouro entre o "povo oprimido" (2009, p.24).

William Oliverio Jr. procura dar conta das possíveis consequências da escolha entre Seymour ou Parham para a origem do movimento. Se a decisiva contribuição do pentecostalismo for a doutrina do batismo com o Espírito Santo como experiência posterior à conversão e evidenciada pela glossolalia, então Parham será considerado o fundador do pentecostalismo moderno. Por outro lado, se o peso for colocado sobre a ideia da reconciliação de Deus com o ser humano e, por sua vez, dos seres humanos uns com os outros, a fundação do movimento será identificada com a Rua Azusa e Seymuor (OLIVERIO, 2012, p. 10). O melhor caminho para esse impasse seria a última opção, contudo, não como evento isolado, mas parte de longa onda de ações carismáticopentecostais.

Na experiência do Espírito, os primeiros carismáticos e pentecostais viviam os carismas entre homens e mulheres, negros e brancos. Como já citado, 
a Rua Azusa foi um movimento profético de promoção e serviço aos marginalizados em um tempo de fortes tensões raciais e socioeconômicas, além de promover o papel da igualdade da liderança masculina e feminina. O teólogo pentecostal Amos Yong explica que a compreensão moderna individualista e espiritualista é uma caricatura que descaracteriza as comunidades pentecostais contemporâneas e suas crenças.

É possível. Contudo, vamos ser mais precisos em relação a isso: a representação anterior é certamente mais predominante entre os privilegiados social e economicamente - leia-se: comunidades anglopentecostais que não lidaram historicamente com a marginalização sócio-política e econômica. Pelo contrário, especialmente as igrejas pentecostais Afro-americanas e Latinas [...] as boas novas de Jesus Cristo fortalecem o discipulado entre os fiéis e contra condições sociais opressoras e - para ser exato - racistas. Para esses irmãos e irmãs, a justificação da alma individual e do coração pessoal sempre se interrelacionou com a justiça social [...]. (YONG, 2019, n.p.).

A perspectiva individualista e espiritualista, próprias da Modernidade, não caberiam à epistemologia pentecostal, cuja experiência de fé desenvolveu combate ao racismo e deu lugar a grupos excluídos política e socialmente (MacROBERT, 1988). A presença do pentecostalismo nas regiões africanas e latino-americanas se revelou como publicamente engajada e libertária. O próprio teólogo asiático erradicado nos EUA, na continuidade de seu argumento, reflete a respeito da política americana na era Trump:

Talvez, o recente desenvolvimento da nossa cena política nacional (norte-americana) tenha nos confrontado com o fato de que nós não temos uma sociedade "daltônica", como nosso pietismo evangélico (histórica e predominantemente branco) presumiu e prefere se autodescrever e declarar. O nacionalismo e a plataforma antiimigração da atual administração, apoiados e populares entre uma grande porcentagem de evangélicos brancos neste país, despertou-nos para o chamado ao Evangelho bíblico que é para pessoas de todas as línguas, tribos e confins da terra. Ainda, essa mesma mensagem é contra os "Césares" deste mundo. De fato, os ensaios a serem apresentados refletem, de uma forma ou de outra, uma perspectiva hermenêutica. Essa perspectiva trata a justiça social como um dos principais temas da Escritura. (YONG, 2019, n.p.).

O pentecostalismo e sua maneira de interpretar a realidade, fé e relações humanas, é visto por alguns pesquisadores e pesquisadoras tal qual outros movimentos contraculturais, pois não se adequava à epistemologia racionalista moderna, ao mesmo tempo, que dialogava com as margens da sociedade. De certa forma, esses movimentos adiantaram, na prática, preocupações presentes 
na linguagem dos direitos humanos, o que se materializaria, por exemplo, na DUDH. Como bem explica Cheryl Bridges Johns,

Uma identidade radicalmente contracultural caracterizava as origens do movimento pentecostal. Na era da "guerra para o fim da guerra", os pentecostais eram pacifistas. No tempo em que a voz das mulheres era excluída da esfera pública, pentecostais ordenavam mulheres ao ministério. Na era da KKK (Ku Klux Klan), pentecostais negros e brancos louvavam juntos. Esse subversivo e revolucionário movimento - o qual não era baseado em ideologia filosófica, nem se estabeleceu a partir de uma reflexão crítica (embora existisse) - tinha dois papeis proféticos: denunciar a estrutura de dominação do status quo e anunciar o padrão de ordenação de Deus. Por sua vez, por causa de suas práticas religiosas extáticas e prática social "anormal", o Pentecostalismo foi atacado pela sociedade em geral e igrejas estabelecidas. (JOHNS, 1995, p. 4-5).

Na Europa do século XIX aconteceram os chamados “avivamentos” entre os protestantes, culminando no final daquele século em várias expressões fervorosas da fé cristã que foram substrato importante para o pentecostalismo nascente no século XX (BURGESS, 2017). Entre suecos batistas da década de 1890, há relatos de experiências muito simulares ao que se popularizou nas igrejas pentecostais mais tarde. O mesmo se pode dizer dos avivamentos galeses, que apesar de curtos períodos, produziram muitas igrejas pentecostalizadas. Os avivamentos ingleses também moveram as massas, e produziram grande adesão. Mas foi nos Estados Unidos do final do século XIX e início do XX que o pentecostalismo adquiriu a forma e mais consistência. Apesar de alguns nomes pioneiros da teologia pentecostal, como o metodista (movimento holiness) Benjamin H. Irwin ${ }^{1}$ e da pregadora María Beulah Woodworth-Etter (1844-1924), chamada de "mãe do pentecostalismo" ${ }^{2}$, foi especialmente com Charles Parham em 1901 e William Seymour a partir de 1906 que o fenômeno se consolidou teologicamente.

Como foi observado, o problema é que Parham foi uma figura polêmica, e acusado de racismo, por isso o esforço para pensar narrativas mais ligadas ao líder afro-americano. Parece que o movimento teria feito justiça em relação a esse tema já nos primórdios, quando Seymour, aluno de Parham, inaugura uma igreja em Los Angeles, que veio a ser mundialmente famosa como a igreja da

\footnotetext{
${ }^{1}$ Stanley Burgess (2017, p. 60) indica que este pregador, depois de uma experiência que ele denominou de "batismo de fogo" ou "terceira bênção", teria organizado uma associação para proclamar essa novidade teológica e religiosa, recebendo críticas da corrente principal do movimento holiness estadunidense.

${ }^{2}$ Meredith Fraser (2019, p. 3) indica que esta pregadora e evangelista pentecostal é conhecida como a "Mãe do movimento pentecostal".
} 
Rua Azusa, dando nova expressão ao movimento e colocando a questão racial no centro do debate. Seymour era um negro que pôde estudar na escola de Parham, segregado dos brancos, tendo que sentar no corredor e assistir às aulas a partir da porta aberta. Seus pais haviam sido escravizados, impactando a visão de mundo do pregador pentecostal, que lutou fervorosamente por uma igreja e sociedade igualitária, em que negros e brancos pudessem conviver respeitosamente.

Essa fase inicial do movimento pentecostal é celebrada como grande contribuição na superação do racismo, embora nem todos os segmentos fossem devidamente influenciados por essa força libertadora. Em 1914, por exemplo, um grupo de pentecostais brancos, descontentes com essa política racial igualitária decidiu criar uma denominação para os brancos, que veio a se chamar Assemblies of God (ADs americanas). A ferida racial nessa igreja encontrou processos de cura e reparação histórica somente no final do século $\mathrm{XX}$, quando intencionalmente as $\mathrm{ADs}$ americanas incluíram os negros na estrutura da igreja, inclusive com pedido de perdão pelo racismo inicial. Recentemente, Jonh Piper (2012), pastor batista estadunidense e teólogo carismático, lançou um livro sobre racismo, onde além de apontá-lo como pecado entre os cristãos (incluindo pentecostais e carismáticos), endossa um pedido de perdão coletivo por esse pecado em sua biografia e igreja. Piper é traduzido no Brasil por várias editoras do segmento evangélico, inclusive pela editora das ADs brasileiras, CPAD (Casa Publicadora das Assembleias de Deus).

As Assembleias de Deus no Brasil (ADs brasileiras), foram fundadas em 1911, com o nome de Missão de Fé Apostólica, e em 1918, resolveram mudar o nome para ADs brasileiras, sem conexão direta com as ADs americanas. Como bem observou Gedeon Alencar (2013), as ADs brasileiras nasceram de forma diferente das americanas, uma vez que a questão racial não dividia a membresia. No entanto, assim como as ADs brasileiras eram formadas por homens e mulheres e não discutiram o machismo, também eram formadas por negros e brancos sem discutir o racismo.

A Assembleia de Deus no Brasil é brasileira? Brasileiríssima. Ela pode não ser a cara do Brasil, mas é um retrato fiel. E um dos principais. É uma das sínteses mais próximas da realidade brasileira. Como o 
Brasil, é moderna, mas conservadora; presente, mas invisível; imensa, mas insignificante; única, mas diversificada; plural, mas sectária; rica, mas injusta; passiva, mas festiva; feminina, mas machista; urbana, mas periférica; mística, mas secular; carismática, mas racionalizada; fenomenológica, mas burocrática; comunitária, mas hierarquizada; grande, mas fracionada; barulhenta, mas calada [...] sofredora, mas feliz. É brasileira. (ALENCAR, 2013, p. 17).

Em sentido mais estrito, é necessário registrar a primazia dos missionários brancos na liderança das igrejas. Quando houve o transpasso para a liderança nacional, espelhou-se o mesmo padrão, embora fossem brasileiros branquiados. Isso não quer dizer que não havia líderes negros, quer destacar que se um negro era líder, isso ocorreu devido ao desempenho extraordinário em comparação com seus pares brancos. Marco Davi Oliveira (2015) investigou a relação entre pentecostalismo e negritude no Brasil, e concluiu que os negros que se convertem ao cristianismo evangélico, optam em sua maioria pelo pentecostalismo, onde podem, de alguma forma, expressar sua negritude com mais liberdade, sem que isso tenha gerado algum movimento revolucionário ou de resistência em relação ao modelo hegemônico pentecostal, que segue governado por brancos. Mas em sentido lato, essa igreja brasileira nasceu progressista em relação à questão racial, tendo negros e brancos partilhando o mesmo ambiente e ministrando uns aos outros.

Os dados dramáticos sobre o contingente populacional de negros e pardos encarcerados, o alto percentual de negros assassinados, a condição de favelização de muitas comunidades de maioria de negros e pardos, etc. não foram tematizados criticamente nem enfrentados do ponto de vista histórico, nem de políticas igualitárias. A falta de reflexão sobre o racismo levou a massa de evangélicos e pentecostais a não o reconhecer em suas fileiras, nem mesmo na sociedade. Impera o discurso vago de que no Brasil não tem racismo, porque aqui supostamente há uma miscigenação “democrática”, onde negros e brancos estariam igualmente na pobreza. Essa falsa ideia de ponto de partida semelhante e a falta de percepção da discriminação para com os negros, em especial, mas também em relação aos indígenas, migrantes e pobres, em geral, impediu a adesão às políticas públicas de reparação histórica, como é o caso das quotas e à conscientização sobre a condição de negritude, com a respectiva valorização cultural e ancestral. 


\section{Conclusão}

Há um flagrante descompasso entre aquele pentecostalismo igualitário em suas origens com o atual pentecostalismo hegemônico, midiático e hierárquico. O movimento é desafiado a retornar à inspiração teológica inicial dos seus começos e ser mais crítico em relação à história, e mais sensível à condição dos marginalizados. A via da afetividade, das metáforas e das narrativas como lócus revelacional da experiência pentecostal, aquela que teria sido a fonte de energia e empoderamento para a ação dos primeiros pentecostais, é referencial esquecido, mas necessário (OLIVEIRA, 2020, p. 324). No pentecostalismo inicial, a ação combinava a dimensão mística com contornos vivenciais no cotidiano, sendo profundamente transformadora da condição social, portanto, profética, no melhor estilo dos profetas bíblicos. É necessário mapear o que ocorreu nas últimas décadas para se levantar possíveis explicações para a flagrante mudança de eixo perceptível em muitos setores negacionistas, sem perder no horizonte, os muitos grupos nas margens que vivem uma autêntica experiência libertadora e suprarracial. Intuímos que tal movimento, mais do que uma nostalgia mítico-fundacional, seria a redescoberta do ethos carismático-pentecostal, pois aponta na direção de práticas, para além de discussões conceituais, libertadoras e humanizadoras.

É possível concluir que os movimentos pentecostais, tanto em seu ethos quanto historicamente, apontam para práticas religiosas de grupos das margens, subvertendo a ordem das relações de poder. A despeito da ausência, exceto em espaços acadêmicos, de discussões teóricas sobre Direitos Humanos e questões raciais, é justo afirmar que há na experiência das comunidades e em suas origens a promoção da igualdade racial, de classe e gênero, a qual se estabelece através da democracia pneumática, especialmente em sua liturgia.

\section{REFERÊNCIAS}

ALENCAR, Gedeon Freire. Matriz pentecostal brasileira: Assembleias de Deus, 1911-2011. Rio de Janeiro: Novos Diálogos, 2013.

ALENCAR, Gedeon Freire; FAJARDO, Maxwell Pinheiro. Pentecostalismos: uma superação da discriminação racial, de classe e de gênero? Estudos de Religião, São Bernardo do Campo, v. 30, n. 2, p. 95-112, 2016. Disponível em: 
https://www.metodista.br/revistas/revistas-ims/index.php/ER/article/view/6847. Acesso em: 30 nov. 2020.

ARCHER, Kenneth J. A Pentecostal Hermeneutic. Spirit, Scripture and Community. Cleveland, Tennessee USA: CPT Press, 2009.

BARTOS, Emil. The Three Waves of Spiritual Renewal of the Pentecostal-Charismatic Movement. Review of Ecumenical Studies Sibiu, Poland, n. 7, v. 1, p. 20-42, 2015.

BRASIL. Lei no 12.288, de julho de 2010. Institui o Estatuto da Igualdade Racial; altera as Leis nos 7.716, de 5 de janeiro de 1989, de 13 de abril de 1995, de 24 de julho de 1985, e 10.778, de 24 de novembro de 2003. Disponível em:

http://www.planalto.gov.br/ccivil_03/_ato2007-2010/2010/lei/l12288.htm. Acesso em: 30 nov. 2020.

BURGESS, Stanley. A evidência do Espírito: as igrejas ocidentais medievais e modernas. In: McGEE, Gary (org.). Evidência inicial: perspectivas históricas e bíblicas sobre a doutrina pentecostal do batismo no Espírito Santo. Natal: Carisma, 2017, p. 39-61.

COMPARATO, Fábio Konder. Fundamentos dos Direitos Humanos. In: INSTITUTO DE ESTUDOS AVANÇADOS DA UNIVERSIDADE DE SÃO PAULO. São Paulo: IEA, 1997. Disponível em:

http://www.iea.usp.br/publicacoes/textos/comparatodireitoshumanos.pdf. Acesso em: 16 jun. 2021.

COX, Harvey. Fire from Heaven: The Rise of Pentecostal Spirituality and the Reshaping of Religion in the Twenty-first Century. Reading, MA: Addison-Wesley, 1995 .

FRASER, Meredith. Maria Beulah Woodworth Etter, the Trance Evangelist. Priscilla Papers, Minneapolis, v. 33, n. 3, p. 3-7, 2019. Disponível em:

https://www.cbeinternational.org/resource/article/priscilla-papers-academicjournal/maria-beulah-woodworth-etter-trance-evangelist. Acesso em: 30 nov. 2020.

INSTITUTO BRASILEIRO DE GEOGRAFIA E ESTATÍSTICA. Censo Demográfico 2010. Rio de Janeiro: IBGE, 2012.

JOHNS, Cheryl Bridge. The Adolescence of Pentecostalism: In Search of a Legitimate Sectarian Identity. Pneuma, Spring, v. 17, p. 3-17, 1995. Disponível em: https://brill.com/view/journals/pneu/17/1/article-p3_2.xml?language=en. Acesso em: 30 nov. 2020.

MacROBERT, Iain. The black roots and white racism of early penteeostalism in the USA. London: MacMillan, 1988.

McGEE, Gary. Evidência Inicial. Perspectivas históricas e bíblicas sobre a doutrina pentecostal do Batismo no Espírito Santo. Natal: Carisma, 2017.

OLIVEIRA, David Mesquiati. Pneumatologia como característica do ser cristão: a contribuição do pentecostalismo ao conjunto do cristianismo. Perspectiva Teológica, Belo Horizonte, v. 52, p. 311-334, 2020. Disponível em: https://www.scielo.br/pdf/pteo/v52n2/2176-8757-pteo-52-2-0311.pdf. Acesso em: 30 nov. 2020. 
OLIVEIRA, David Mesquiati; ROCHA, A. R. Pentecostalismo e empoderamento de identidades marginalizadas. Pistis \& Práxis, Curitiba, v. 10, p. 722-741, 2018. Disponível em:

https://periodicos.pucpr.br/index.php/pistispraxis/article/view/24520/23210. Acesso em: 30 nov.2020.

OLIVEIRA, David Mesquiati; TERRA, Kenner R. C. Experiência e hermenêutica pentecostal: reflexões e propostas para a construção de uma identidade teológica. Rio de Janeiro: CPAD, 2018.

OLIVEIRA, Marco Davi. A religião mais negra do Brasil: por que os negros fazem opção pelo pentecostalismo? Viçosa: Ultimato, 2015.

OLIVERIO, L. William Jr. Theological Hermeneutics in the Classical

Pentecostal Tradition: A Typological Account. Leiden: BRILL, 2012.

ORGANIZAÇÃO DAS NAÇÕES UNIDAS. Declaração Universal dos Direitos

Humanos. 10 dez. 1948. Disponível em: https://www.unicef.org/brazil/declaracaouniversal-dos-direitos-humanos. Acesso em: 30 nov. 2020.

PALHARES, Ricardo Henrique. A mudança no cenário religioso brasileiro: o rearranjo espacial do movimento pentecostal. Revista Verde Grande de Geografia e Interdisciplinaridade. Montes Claros, v. 1, n. 2, p. 19-29, 2019.

PARHAM, Charles F. Uma voz clamando no deserto. São Paulo: Reflexão, 2020.

PIPER, John. O racismo, a cruz e o cristão: a nova linhagem em Cristo. São Paulo: Vida Nova, 2012.

RIVERO, Jean; MOUTOUH, Hugues. Liberdades públicas. São Paulo: Martins Fontes, 2006.

ROBECK JR, Cecil M. The Azusa Street Mission and Revival: The Birth of the Global Pentecostal Movement. Nashville: Thomas Nelson, 2006.

SANTOS, Boaventura de Sousa. Se Deus fosse um ativista dos Direitos

Humanos. 2. ed. São Paulo: Cortez, 2014.

SMITH, James K. A. What Hath Cambridge to do with Azusa Street? Radical Orthodoxy and Pentecostal Theology in Conversation. PNEUMA: The Journal of the Society for Pentecostal Studies, v. 25, n. 1, p. 97-114, 2003.

WOLKMER, Antonio Carlos. Cultura jurídica moderna, humanismo renascentista e Reforma Protestante. Sequência, Florianópolis, n. 50, p. 9-27, 2005.

YONG, A. Foreword. In: HARRIS, Antipas L.; PALMER, Michael D. (ed.). The Holy Spirit and Social Justice: Interdisciplinary Global Perspectives. Scripture and Theology. Lanham, MD, 2019.

YONG, Amos. Academic glossolalia? Pentecostal scholarship, multidisciplinarity, and the science-religion conversation. Journal of Pentecostal Theology, USA, v. 14, n. 1, p. 61-80, 2005. 